\title{
Use of Yokukansan (TJ-54) in the treatment of neurological disorders: A review
}

\author{
S. de Caires, V. Steenkamp* \\ Department of Pharmacology, Faculty of Health Sciences, University of Pretoria
}

Short title: TJ-54

*Address for correspondence and reprints:

Prof $\vee$ Steenkamp

Department. of Pharmacology

School of Medicine

Faculty of Health Sciences

University of Pretoria

PO Box 2034

Pretoria 0001

South Africa

Tel: +27-12-319 2547

Fax: +27-12-319 2411

e-mail: vanessa.steenkamp@up.ac.za 


\section{Abstract}

Kampo herbal remedies are reported to have a wide range of indications and have attracted attention due to reports suggesting that these remedies are effective when used in disease treatment while maintaining a favourable quality of life. Yokukansan, also known as TJ-54, is composed of seven herbs; Angelica acutiloba, Atractylodes lancea, Bupleurum falcatum, Poria cocos, Glycyrrhiza uralensis, Cnidium officinale, and Uncaria rhynchophylla. Yokukansan is used to treat insomnia and irritability as well as screaming attacks, sleep tremors and hypnic myoclonia, and neurological disorders which include dementia and Alzheimer's disease - the focus of this article. It is concluded that Yokukansan is a versatile herbal remedy with a variety of effects on various neurological states, without reported adverse effects. Traditional herbal medicines consist of a combination of constituents which account for the clinical effect seen. Likewise, the benefits of Yokukansan are probably attributable to the preparation as a whole, rather than to individual compounds.

Keywords: Alzheimer's disease, dementia, herbal remedy, Kampo, TJ-54, Yokukansan

\section{Introduction}

Kampo medicines are traditional herbal medicines which have been used in China for more than 2000 years. Chinese herbal remedies were first introduced into Japan around the $5^{\text {th }}$ century and have since been modified by the Japanese (Okamoto et al., 2004). These Kampo herbal remedies are reported to have a wide range of 
indications and have attracted attention due to reports suggesting that the remedies are effective when used in disease treatment while maintaining a favourable quality of life (Mizukami et al., 2009). The Japanese Ministry of Health, Labor and Welfare has approved more than 120 Kampo prescriptions for use in clinical practice (Takeda et al., 2008).

It is known that the effects of Japanese traditional herbal medicines differ in each case according to the 'Sho' of each individual (Aizawa et al., 2002). The word 'Sho' can be roughly translated in English as symptoms, signs or evidence (Terasawa, 2004). 'Sho' encompases psychic and somatic symptoms as well as the patient's constitution and physical condition (Kanba et al., 1991). Ancient Kampo physicians abhorred invasions into a patient's body and examinations such as biopsy or endoscopy were unimaginable. The only approaches left were; visual observation, listening to the sounds made by the patient's body, smelling and touching the patient and listening to what they say (Terasawa, 2004). Although this seems to be a very qualitative approach to disease diagnosis, biochemical and pharmacological research has found evidence that the physician's intuition has a firm scientific basis, even though some of the 'Sho' and herbal formulae in Kampo still await the discovery of their molecular basis (Terasawa, 2004).

Yokukansan, also called TJ-54, is a Kampo prescription known as Yi-gan-san in Chinese. It was developed in 1555 by Xue Kai as a remedy for agitation and restlessness in children (Iwasaki et al., 2005). It is composed of seven herbs; Angelica acutiloba L. (Umbelliferae), Atractylodes lancea DC. (Compositae), Bupleurum falcatum L. (Umbelliferae), Poria cocos Wolf. (Polyporaceae), Glycyrrhiza 
uralensis (Leguminosae), Cnidium officinale Makino (Umbelliferae), and Uncaria rhynchophylla Schreb. (Rubiaceae) in a ratio of 3:4:2:4:1.5:3:3, respectively. The mixed dried extract of these herbs are sold in packages containing $2.5 \mathrm{~g}$ and is recommended to be taken three times daily before meals (Tateno et al., 2008). Yokukasan is used to treat insomnia and irritability as well as screaming attacks, sleep tremors and hypnic myoclonia (Ishii, 2000; Aizawa et al., 2002; Okamoto et al., 2004). Noting the increasing life expectancy of the Japanese population, geriatricians have begun to use traditional regimens to treat dementia symptoms in the elderly and Yokukansan is one of the Kampo medicines being used. This review focuses on the use of Yokukansan in treating neurological disorders which include dementia and Alzheimer's disease.

\section{Indications of yokukansan}

\section{(i) Dementia}

Behavioural and psychological symptoms of dementia (BPSD) include aggression, agitation, screaming, wandering, hallucinations, and delusions which occur in 20$80 \%$ of such patients (Lawlor, 2004; Mizukami et al., 2009). The pathophysiology of BPSD is related to an imbalance between the different neurotransmitters; acetylcholine, serotonin, dopamine and noradrenaline (Lanari et al., 2006). Adverse reactions such as deterioration of cognitive function, extrapyrimidal symptoms and gait disturbance, limit the use of atypical antipsychotics in the treatment of these symptoms (Schneider et al., 2006). Therefore other treatments for dementia symptoms which can be used more safely are warranted. A possible solution is herbal medicines which have been used for millennia with apparent safety and 
efficacy in China, Korea, Taiwan and Japan for the treatment of dementia in the elderly (Iwasaki et al., 2005).

Alzheimer's disease $(A D)$ is a progressive neurodegenerative disorder characterised by the accumulation of amyloid $ß(A ß)$-plaques in the cerebral cortex leading to loss of neurons and memory dysfunction, accompanied by BPSD (Cha et al., 2001; Blennow et al., 2006). Tabuchi et al. (2009) investigated the effects of Yokukansan on learning and non-cognitive disturbances in Tg2576 mice expressing the human form of the APP6955WE gene (APP-Tg mice), which is considered to be an animal model of AD. Yokukansan (0.5\% and $1.0 \%)$ was given to mice for 10 months, after which evaluation of learning and non-cognitive disturbances was performed using the Morris water-maze test, elevated plus-maze test and open-field test. Results showed Yokukansan to improve learning and non-cognitive defects as well as to decrease anxiety in the APP-Tg(+) mice.

Mizukami et al. (2009) reported the effectiveness and safety of Yokukansan for the treatment of dementia symptoms in 106 patients diagnosed with AD. BPSD and cognitive functions were evaluated using the Neuropsychiatric Inventory (NPI) and the Mini-Mental State Examination (MMSE), respectively. Patients who had received Yokukansan (7.5g t.i.d.) for 4 weeks showed significant $(p<0.05)$ improvement in the NPI scores during the treatment period as well as in NPI subscales (delusions, hallucinations, agitation/aggression, depression, anxiety and irritability) which lasted for 1 month. Although the treatment did not show any effect on cognitive function, there were no serious adverse effects and it is suggested that Yokukansan is 
effective and well tolerated in BPSD patients (Mizukami et al., 2009). In another clinical study fifteen AD patients were treated with $2.5 \mathrm{~g}$ of Yokukansan three times a day, for 12 weeks (Monji et al., 2009). The NPI examinations revealed significant improvement $(p<0.001)$ in the treatment group with no improvement in the control group. The authors concluded that Yokukansan improved BPSD and reduced the doses of antipsychotics required for treatment of BPSD in elderly patients. No adverse effects were noted. Furthermore, improvement of behavioural and psychological symptoms such as agitation, aggression and irritability were noted in 52 Alzheimer's patients who received $2.5 \mathrm{~g}$ of Yokukansan, 3 times a day for 4 weeks (Iwasaki et al., 2005).

\section{(ii) Neurotransmitter systems}

Glutamate is a major excitatory neurotransmitter which is involved in many brain functions including cognition, memory, learning, as well as other neuronal functions such as synapse induction and elimination (Takeda et al., 2008). Glutamate performs its signalling functions via glutamate receptors, however, excessive activation of these receptors is harmful to neurons just as high concentrations of extracellular glutamate are toxic to neurons (Danbolt, 2001; Takeda et al., 2008). Glutamate excitotoxicity, which is induced by excessive glutamate in the synaptic cleft, causes neuronal cell death and can be seen in many neurological diseases including stroke, epilepsy and Alzheimer's (Choi and Rothman, 1990; Lipton and Rosenberg, 1994; Obrenovitch and Urenjak, 1997). This disturbance in the glutamatergic system may be associated with behavioural and psychological symptoms in patients with dementia (Steele et al., 1990). 
The effect of Yokukansan on thiamine-deficient rats was investigated and results indicated that Yokukansan ameliorated degeneration of neuronal and astroglial cells in the rat brain stem, cerebral cortex and hippocampus, which are responsible for learning, memory and various psychological functions (Ikarashi et al., 2006). Takeda et al. (2008) showed that administration of Yokukansan (300 mg/kg body weight) to zinc-deficient (elevated glutamate) rats, significantly suppressed the increase in extracellular concentrations of glutamate and aspartate in the hippocampus of these rats after stimulation with $100 \mathrm{mM} \mathrm{KCl}$. This suggests that Yokukansan is involved in the modulation of excitatory neurotransmitter systems.

In an attempt to clarify the mechanism of Yokukansan against glutamate-mediated excitotoxicity, Kawakami et al. (2009) investigated the effects of Yokukansan on glutamate uptake function as well as its effect on glutamate-induced neuronal death, using cultured cells. Results showed Yokukansan to improve glutamate uptake and inhibited glutamate-induced neuronal death in a dose-dependent manner. This suggests that Yokukansan exerts a neuroprotective effect by amelioration of the dysfunction of astrocytes and also by direct protection of the neuronal cells (Kawakami et al., 2009).

Abnormalities of the serotonergic 5-hydroxytryptamine (5-HT) system have been associated with BPSD of Alzheimer's patients (Garcia-Alloza et al., 2005). Egashira et al. (2008) investigated the effect of Yokukansan on the head-twitch response in 
mice induced by 2,5-dimethoxy-4-iodoamphetamine (DOI), which is a $5-\mathrm{HT}_{2 \mathrm{~A} / 2 \mathrm{C}}$ agonist. Acute treatment with Yokukansan (100 and $300 \mathrm{mg} / \mathrm{kg} \mathrm{p.o)} \mathrm{was} \mathrm{shown} \mathrm{to}$ provide no improvement of the head-twitch response, but repeated treatment with $300 \mathrm{mg} / \mathrm{kg}$ p.o. of Yokukansan significantly inhibited the twitch response $(p<0.05)$ and also decreased the expression of $5-\mathrm{HT}_{2 \mathrm{~A}}$ receptors $(\mathrm{p}<0.01)$ in the pre-frontal cortex of the mice.

\section{(iii) Sleep disorders}

Studies have shown that dementia patients experience a decrease in the amount of slow wave sleep (Prinz et al., 1982) and rapid eye movement (REM) sleep (Satlin et al., 1991), resulting in sleep disturbances. The effects of Yokukansan $(2.5 \mathrm{~g}$, before meals, three times a day for 4 weeks) on both BPSD and sleep structure in dementia patients showed significant improvements $(p<0.05)$ in NPI scores, reduced delusions, hallucinations, agitation/aggression, anxiety and irritability as well as increases in total sleep time (Shinno et al., 2008). The authors suggested that the serotonergic and GABAergic effects of Yokukansan are responsible for the beneficial effects seen.

Patients suffering from somatoform disorder often complain of headache, tenseness, fatigue and tinnitus (Hiller et al., 1997). Tinnitus is characterised by continuous auditory perception of various sounds such as buzzing, ringing and tends to cause insomnia, irritability and depressive mood. A case of a 44 year old woman who had been suffering from tinnitus and insomnia for 3 years without successful treatment 
was reported (Hideki et al., 2005). The patient was later diagnosed with somatoform disorder and sulpiride (150 mg per day) was chosen as treatment, however, the tinnitus and headache were still present after 3 weeks. When Yokukansan (dose not provided) was added to the sulpiride treatment, the tinnitus, headache and insomnia cleared within 2 weeks, suggesting the effectiveness of Yokukansan in the treatment of tinnitus in undifferentiated somatoform disorder complicated with headache and insomnia.

Yokukansan $(7,5 \mathrm{~g} /$ day, 3 times daily for 3 days) significantly $(p<0.05)$ extended the total sleep time of 20 adult male patients compared to the control group (Aizawa et al., 2002). The former therefore exhibits a profile similar to that of benzodiazepines, which are commonly known to improve sleep (Nishino et al., 1995; Aizawa et al., 2002).

\section{(iv) Personality disorders}

Yokukansan is reported to be valuable in the treatment of various emotional symptoms in borderline personality disorder (Miyaoka et al., 2007a), tardive dyskinesia and psychotic symptoms in schizophrenia (Miyaoka et al., 2007b). There is currently no definite treatment for borderline personality disorder (BPD), because despite the efficacy of some medications, side effects do seem to limit their use (Miyaoka et al., 2007a). A 12-week open-label study investigated the effect of Yokukansan (6.4 $\pm 1.9 \mathrm{~g}$ daily) on 25 female BPD patients. Significant improvements $(p<0.0001)$ in the various symptoms of BPD, including depression, aggression, 
impulsivity and anxiety were noted, without significant side effects (Miyaoka et al., 2007a). Furthermore, a decrease in $\mathrm{y}$-aminobutyric acid (GABA) receptors as well as serotonin levels was reported in such patients (Hansenne et al., 2002; Friedel, 2004).

Tardive dyskinesia (TD) in schizophrenic patients consists of abnormal, involuntary, irregular movements of the muscles of the head, limbs, and trunk which are often irreversible (Chouinard et al., 1988). Serotonergic and dopaminergic neurotransmitter systems are implicated in tardive dyskinesia (Goldman, 1976; Seibyl et al., 1989). In an open-label study performed by Miyaoka et al. (2008), 22 patients with schizophrenia who had neuroleptic-induced tardive dyskinesia were given $7.5 \mathrm{~g} /$ day of Yokukansan for 12 weeks. A significant improvement in tardive dyskinesia and psychotic symptoms was reported $(p<0.0001)$. The authors suggest that the effect of $5-\mathrm{HT}_{2 \mathrm{~A}}$ antagonism by Yokukansan can restore and maintain "normal" dopamine function in patients with schizophrenia and may produce antipsychotic effects without including sedation or extrapyramidal symptoms.

\section{Other effects associated with neurological states}

Biochemical and histological investigations carried out by Tabuchi et al. (2009) suggested that the ameliorative effect of Yokukansan on cognitive and non-cognitive symptoms in Alzheimer's patients is independent of $A ß$ deposition. $A ß$ also has an effect on cholinergic and serotonergic neurons (Harkany et al., 1995; 2001) as well as glutamatergic neurons (Fitzjohn et al., 2001). This means that $A ß$ deposition 
leads to impaired cognitive and non-cognitive functions via long-term potentiation of the dysregulated neuron systems (Jacobson et al., 2006). Yokukansan is said to inhibit excessive glutamate release in the hippocampus of zinc-deficient rats (Takeda et al., 2008), reduce expression of 5-HT receptors in the prefrontal cortex of rats (Egashira et al., 2008) and increase choline acetyltransferase activity and acetylcholine levels in experimental animals (Ito, 1997; Yabe et al., 2005). Recently, Yokukansan was demonstrated to inhibit Aß-induced cytotoxicity in primary culture of rat cortical neurons (Tateno et al., 2008), indicating that Yokukansan exerts a protective effect on glutamate-induced cell death via an anti-cytotoxic mechanism.

\section{Plant components of Yokukansan and their relevant biological activities/toxicities}

Some of the compounds in Yokukansan have an affinity for dopamine and serotonin receptors, antagonising dopamine receptors and hence extrapyrimidal side effects are not present when using Yokukansan as opposed to most antipsychotic treatments (Iwasaki et al., 2005).

Angelica acutiloba has been reported to have ameliorative effects on cognitive impairment induced by scopolamine (Hatip-Al-Khatib et al., 2004), ischemia (Zhao et al., 2005) and hypoperfusion (Murakami et al., 2005). This plant also affects GABA and 5-HT receptors (Liao et al., 1995), further explaining the ameliorative effect of Yokukansan on BPD symptoms (Miyaoka et al., 2007a). A. acutiloba contains alkylphthalide derivatives and furanocoumarins, both of which have been shown to 
possess acetylcholinesterase inhibitory activity (Mitsuhashi et al., 1960; Kang et al., 2001). This plant should not be taken with warfarin, heparin, aspirin, nonsteroidal anti-inflammatory drugs nor other antioxidants as it may affect blood clotting.

Uncaria rhynchophylla has a potent anti-aggregation effect on $A ß$ proteins, a deposition which is characteristic of Alzheimer's disease. The water extract of $U$. rhynchophylla contains oxindole and indole alkaloids which possess neuroprotective properties (Fujiwara et al., 2006; Tabuchi et al., 2009). This plant also contains the alkaloids hirsuteine and hirsutine which are known for their protective effects against glutamate-induced neuronal death (Shimada et al., 1999). Epicatechin, caffeic acid and quecertin, found in this plant, have been shown to protect against oxidative damage by $\mathrm{H}_{2} \mathrm{O}_{2}$ in NG108-15 cells (Mahakunakorn et al., 2004). The latter is an important function seeing that stimulation of $N$-methyl $D$-aspartate (NMDA) receptors by glutamate (especially excessive glutamate such as with dementia), causes an overload of intracellular $\mathrm{Ca}^{2+}$ which in turn activates neurons to produce excessive nitric oxide and other reactive oxygen species which cause neuronal death (Weikert et al., 1997). Furthermore, U. rhynchophylla can block NMDA-induced neuronal death by inhibiting the current in these neurons (Lee et al., 2003; Sun et al., 2003). The compounds, rhynchophylline and isorhynchophylline, have been reported to antagonise the NMDA receptor (Kang et al., 2002), possibly making these constituents of Yokukansan an important contributor to its neuroprotective effect. The alkaloid, hirsutine, possesses local anaesthetic properties, showing "curare-like" ability on neuromuscular transmission (Jones, 1994). The pentacyclic oxindole alkaloids seem to be responsible for anti-inflammatory activity (Aguilar et al., 2002). This species seems to be the most important of the seven plant species in the 
treatment of neurophsychiatric conditions (Tateno et al., 2008). Uncaria may potentiate the action of antihypertensive drugs and should not be used by patients receiving immunosuppressive therapy or with autoimmune disorders due to its' potential immunostimulating effects.

Poria cocos is used in Korea and Japan to treat age-related brain disorders and to improve cognitive and memory function in old age (Adams et al., 2007). The plant contains several monosaccharides, triterpene derivatives and 15 amino acids (Chihara et al., 1970; Kanematsu and Natori, 1970; Lee et al., 2004). Poria has been reported to improve cerebral blood flow (Jingyi et al., 1997), promote hippocampal long-term potentiation in vivo (Smriga et al., 1995), improve memory and inhibit acetylcholinesterase activity (Liu et al., 1993). Poria has been reported to exert anti-inflammatory effects (Nukaya et al., 1996; Cuellar et al., 1997). No adverse reactions or toxicity has been reported for Poria.

Atractylodes lancea contains sesquiterpenoid glycosides (atractyloside), Ltryptophan and syringin (Yahara et al., 1989). Atractyloside is a known hepatotoxin (Wainright et al., 1977). Cnidium officinale and Glycyrrhiza uralensis have both been shown to contribute to the repairing of $A \beta$-induced memory loss in mice with Alzheimer's disease (Tohda et al., 2003). G. uralensis contains the flavone, liquiritin, which has been shown to possess antidepressant-like effects in induced depression rat models (Zhao et al., 2008). Other compounds present in Glycyrrhiza are the glycoside, glycyrrhizin, glycyrrhizic acid and glycyrrhizinate (Isbrucker and Burdock, 2006). Glycyrrhetic acid has anti-inflammatory and antiarthritic activity and a number 
of compounds present in this plant possess antioxidant activity (Isbrucker and Burdock, 2006). High doses of the plant used for extended periods of time may cause hyperkalemia, mineralocorticoid hypertension and paralysis of extremities (Sigurjonsdottir et al., 1995; Elinav and Chajek-Shaul, 2003; Schapera, 2003).

Bupleurum falcatum is listed as one of the seven historical Korean plants which are used for the general improvement of cognition and memory function in old age and a methanolic extract of this plant was shown to inhibit acetylcholinesterase by $24.7 \%$ (Oh et al., 2004). Bupleurum contains triterpene saponins known as saikosaponins as well as pectin-like polysaccharides (bupleurans) (Hocking, 1997). Antiinflammatory activity has been reported to be increased by saikosides (Chevallier, 1996). Although the toxicity profile is low, Bupleurum has caused sedative effects in some patients (Bone, 1996).

In summary, a review of the literature led us to the conclusion that Yokukansan is a versatile herbal remedy with a variety of effects on various neurological states with no reported adverse effects. Traditional herbal medicines consist of a combination of constituents which account for the clinical effect seen. Likewise, the benefits of Yokukansan are probably attributable to the preparation as a whole, rather than to individual compounds. 


\section{References}

Adams M, Gmunder F, Hamburger M. 2007. Plants traditionally used in age related brain disorders -A survey of ethnobotanical literature. J Ethnopharmacol 113: 363368.

Aguilar JL, Rojas P, Marcelo A, Plaza A, Bauer R, Reininger E, Klaas CA, Merfort I. 2002. Anti-inflammatory activity of two different extracts of Uncaria tomentosa (Rubiaceae). J Ethnopharmacol 81: 271-276.

Aizawa R, Kanbayashi T, Saito Y, Ogawa Y, Sugiyama T, Kitajima T, Kaneko Y, Abe M, Shimizu T. 2002. Effects of Yoku-kan-san-ka-chimpi-hange on the sleep of normal healthy adult subjects. Psychiatry Clin Neurosci 56: 303-304.

Blennow K, de Leon MJ, Zetterberg H. 2006. Alzheimer's disease. Lancet 368: 387403.

Bone K. 1996. Bupleurum: a natural steroid effect. Can J Herbalism 41: 22-25.

Cuellar MJ, Giner RM, Recio MC, Just M, Manez JS, Rios J. 1997. Effect of the basidiomycete Poria cocos on experimental dermatitis and other inflammatory conditions. Chem Pharm Bull 45: 492-494. 
Cha JHJ, Farrel LA, Ahmed SF, Frey A, Hsia-Ashe KK, Young AB, Penney JB, Locascio JJ, Hyman BT, Irizarry MC. 2001. Glutamte receptor dysregulation in the hippocampus of transgenic mice carrying mutated human amyloid precursor protein. Neurobiol Dis 8: 90-102.

Chevallier A. 1996. Encyclopedia of Medicinal Plants. DK Publishing: New York, p68.

Chihara G, Hamuro J, Maeda Y, Arai Y. 1970. Antitumor polysaccharide derived chemically from natural glucan (Pachyman). Nature 225: 943-944.

Choi DW, Rothman SM. 1990. The role of glutamate neurotoxicity in hypoxicischemic neuronal death. Ann Rev Neurosci 13: 171-182.

Chouinard G, Annable L, Ross-Chouinard A, Mercier P. 1988. A 5-year prospective longitudinal study of tardive dyskinesia: factors predicting appearance of new cases. J Clin Psychopharmacol 8(suppl):21S-26S.

Danbolt NC. 2001. Glutamate uptake. Prog Neurobiol 65: 1-105.

Egashira N, Iwasaki K, Ishibashi A, Hayakawa K, Okuno R, Abe M, Uchida N, Mishima K, Takasaki K, Nishimura R, Oishi R, Fujiwara M. 2008. Repeated administration of Yokukansan inhibits DOl-induced head-twitch response and decreases expression of 5-hydroxytryptamine $(5-\mathrm{HT}) 2 \mathrm{~A}$ receptors in the prefrontal cortex. Prog Neuropsychopharmacol 32: 1516-1520. 
Elinav E, Chajek-Shaul T. 2003. Licorice consumption causing severe hypokalemic paralysis. Mayo Clin Proc 78: 767-768.

Fitzjohn SM, Morton RA, Kuenzi F, Rosahl TW, Shearman M, Lewis H, Smith D, Raynolds DS, Davies CH, Collingridge GL, Seabrook GR. 2001. Agerelated impairment of synaptic transmission but normal long-term potentiation in transgenic mice that overexpress the human APP695SWE mutant form of amyloid precursor protein. J Neurosci 21: 4691-4698.

Friedel RO. 2004. Dopamine dysfunction in borderline personality disorder: a hypothesis. Neuropsychopharmacol 29: 1029-1039.

Fujiwara H, Iwasaki K, Furukawa K, Seki T, He M, Maruyama M, Tomita N, Kudo Y, Higuchi M, Saido TC, Maeda S, Takashima A, Hara M, Ohizumi Y, Arai H. 2006. Uncaria rhynchophylla, a Chinese medical herb, has potent antiaggregation effects on Alzheimer's ß-amyloid proteins. J Neurosci Res 84: 427-433.

Garcia-Alloza M, Gil-Bea FJ, Diez-Ariza M, Chen CP, Francis PT, Lasheras B, Ramirez MJ. 2005. Cholinergic-serotonergic imbalance contributes to cognitive and behavioural symptoms in Alzheimer's disease. Neuropsychologia 43: 442-449. 
Goldman D. 1976. Treatment of phenothiazine-induced dyskinesia. Psychopharmacol Bull 12: 7-10.

Hansenne M, Pitchot W, Ansseau M. 2002. Serotonin, personality and borderline personality. Acta Neuropsychiatry 14: 66-70.

Harkany T, Lengyel Z, Soós K, Penke B, Luiten PGM, Gulya K. 1995. Cholinotoxic effects of ß-amyloid(1-42) peptide on cortical projections of the rat nucleus basalis magnocellularis. Brain Res 695: 71-75.

Harkany T, O’Mahony S, Keijser J, Kelly JP, Kónya C, Borostyánko ZA, Go TJ, Zarándi M, Penke B, Leonard BE, Luiten PGM. 2001. ß-Amyloid(1-42)-induced cholinergic lesions in rat nucleus basalis bidirectionally modulate serotonergic innervation of the basal forebrain and cerebral cortex. Neurobiol Dis 8: 667-678.

Hatip-Al-Khatib I, Egashira N, Mishima K, Iwasaki K, Iwasaki K, Kurauchi K, Inui K, Ikeda T, Fujiwara M. 2004. Determination of the effectiveness of compounds of herbal medicine Toki-Shakuyaku-San and fractions of Angelica acutiloba in improving the scopolamine-induced impairment of rat's special cognition in eightarmed radial maze test. J Pharmacol Sci 96: 33-41.

Hideki O, Toshihiko O, Masatoshi I, Takeuchi T. 2005. Effects of Yoku-kan-san on undifferentiated somatoform disorder with tinnitus. Eur Psychiatry 20: 74-75. 
Hiller W, Janca, A, Burke KC. 1997. Association between tinnitus and somatoform disorders. J Psychosom Res 43(6): 613-624.

Hocking G. 1997. A dictionary of natural products. Plexus Publ Inc: Medford NJ pages 132-133.

Ikarashi Y, lizuka S, Imamura S, Kanno H, Yamaguchi T, Yuzurihara M, Kase Y, Takeda S. 2006. Yokukansan inhibits memory disturbance, anxiety and neurological symptoms in thiamine-deficient rats. Dementia 20(Suppl): 49.

Isbrucker RA, Burdock GA. 2006. Risk and safety assessment on the consumption of Licorice root (Glycyrrhiza sp.), its extract and powder as food ingredient, with emphasis on the pharmacology and toxicology of glycyrrhizin. Regul Toxicol Pharmacol 46; 167-192.

Ishii K. 2000. Sleep disorders in the elderly and Kampo medicine. Kampo and Newest Therapy 9: 21-26.

Ito T. 1997. Regulatory effects of yoku-kan-san-ka-chimpi-hange and saikokaryukotsu- borei-to on function of the central nervous system in mice. Prog Med 17: 823-830.

Iwasaki K, Satoh-Nakagawa T, Maruyama M, Monma Y, Nemoto M, Tomita N, Tanji H, Fujiwara H, Seki T, Fujii M, Arai H, Sasaki H. 2005. A randomized, observer-blind, 
controlled trial of the traditional Chinese medicine Yi-Gan San for improvement of behavioural and psychological symptoms and activities of daily living in dementia patients. J Clin Psychiatry 66(2): 248-252.

Jacobsen JS, Wu CC, Redwine JM, Comery TA, Arias R, Bowlby M, Martone R, Morrison JH, Pangalos MN, Reinhart PH, Bloom FE. 2006. Early-onset behavioral and synaptic deficits in a mouse model of Alzheimer's disease. Proc Natl Acad Sci USA 103: 5161-5166.

Jingyi W, Yasuhiro M, Naoya H, Seok RC, Yoshiharu $Y$, Nagara T, Fumiko T, Shigeru M, Junji K. 1997. Observation on the effects of Chinese medicine zhenxuanyin for improving cerebral blood flow in rats with cerebral ischemia. $\mathrm{J}$ Trad Chin Med 17: 299-303.

Jones K. 1994. The herb report: Una de dato, life-giving vine of Peru. AHA 10: 4.

Kanba S, Mizuno M, Yagi G, Asai M. 1991. Effects of Tsumura Yoku-kan-san-kachimpi-hange on neurosis. Nikkei Med 10: 72-73 (in Japanese)

Kanematsu A, Natori S. 1970. Triterpenoids of Hoelen (fuling), sclerotia of Portia cocos. II. 33-Hydroxylamntosta-7,9(11),24-trien-21-oicacid. Chem Pharm Bull 18: 779-783. 
Kang SY, Lee KY, Sung SH, Park MJ, Kim YC. 2001. Coumarins isolated from Angelica gigas inhibit acetylcholinesterase: srtructure-activity relationships. J Nat Prod 64: 683-685.

Kang TH, Murakai Y, Matsumoto K, Takayama H, Kitajima M, Aimi N, Watanabe H. 2002. Rhynchophylline and isorhynchophylline inhibit NMDA receptors expressed in Xenopus oocytes. Eur J Pharmacol 455: 27-34.

Kawakami Z, Kanno H, Ueki T, Terawaki K, Tabuchi M, Ikarashi Y, Kase Y. 2009. Neuroprotective effects of Yokukansan, a traditional Japanese medicine, on glutamate-mediated excitotoxicity in cultured cells. Neuroscience 159: 1397-1407.

Lanari A, Amenta F, Silvestrelli G, Tomassoni D, Parnetti L. 2006. Neurotransmitter deficits in behavioral and psychological symptoms of Alzheimer's disease. Mech Age Develop 127(2): 158-165.

Lawlor BA. 2004. Behavioural and psychological symptoms in dementia: the role of atypical antipsychotics. J Clin Psychiatry 65(11): 5-10.

Lee J, Son D, Lee P, Kim D-K, Shin M-C, Jang M-H, Kim C-J, Kim Y-S, Kim H. 2003. Protective effect of methanol extract of Uncaria rynchophylla against excitotoxicity induced by N-methyl-D-aspartate in rat hippocampus. J Pharmacol Sci 92: 70-73. 
Lee KY, You HJ, Jeong HG, Kang JS, Kim HM, Rhee SD, Jeon YJ. 2004. Polysaccharide isolated from Poria cocos sclerotium induces NF-kappaB/Rel activation and iNOS expression through the activation of p38 kinase in murine macrophages. Int Immunopharmacol 4: 1029-1038.

Liao JF, Jan YM, Huang SY, Wang HH, Yu LL, Chen CF. 1995. Evaluation with receptor binding assay on the water extracts of ten CNS-active Chinese herbal drugs. Proc Natl Sci Counc Repub China, B 19(13): 151-158.

Lipton SA and Rosenberg PA. 1994. Excitatory amino acids as a final common pathway for neurological disorders. N Eng J Med 330: 613-622.

Liu Z, Yang Y, Zheng B. 1993. Effect of improving memory and inhibiting acetylcholinesterase activity by invigorating-qi and warming-yang recipe. Zhongguo Zhang Xi Yi Jie He Za Zhi 13: 646, 675-676.

Mahakunakorn P, Tohda M, Murakami Y, Matsumoto K, Watanabe H. 2004. Antioxidant and free radical-scavenging activity of chotosan and its related constituents. Biol Pharm Bull 27: 38-46. 
Mitsuhashi H, Nagai U, Muramatsu T, Tashiro H. 1960. Studies on the constituents of Umbelliferae plants. II. Isolation of the active principles of Ligusticum roots. Chem Pharm Bull 8: 243-245.

Miyaoka T, Furuya M, Yasuda H, Hayashia M, Inagaki T, Horiguchi J. 2007a. Yi-gan san for the treatment of borderline personality disorder: an open-label study. Prog Neuropsychopharmacol 32: 150-154.

Miyaoka T, Furuya M, Yasuda H, Hayashida M, Nishida A, Inagaki T, Horiguchi J. 2007b. Yi-gan san for the treatment of neuroleptic-induced tardive dyskinesia: An open-label study. Prog Neuropsychopharmacol 32: 761-764.

Miyaoka T, Yasukawa R, Yasuda H, Hayashida M, Inagaki T, Horiguchi J. 2008. Minocycline as adjunctive therapy for schizophrenia: an open-label study. Clin Neuropharmacol 31:287-292.

Mizukami K, Asada T, Kinoshita T, Tanaka K, Sonohara K, Nakai R, Yamaguchi K, Hanyu H, Kanaya K, Takao T, Okada M, Kudo S, Kotoku H, Iwakiri M, Kurita H, Miyamura T, Kawasaki Y, Omori K, Shiozaki K, Odawara T, Suzuki T, Yamada S, Nakamura Y, Toba K. 2009. A randomized cross-over study of traditional Japanese medicine (kampo), yokukansan, in the treatment of behavioural and psychological symptoms of dementia. Int J Neuropsychopharmacol 12: 191-199. 
Monji A, Takita M, Samejima T, Tahaishi T, Hashimoto K, Matsunaga H, Oda M, Sumida Y, Mizoguchi Y, Kato T, Horikawa H, Kanba S. 2009. Effects of yokukansan on the behavioural and psychological symptoms of dementia in elderly patients with Alzheimer's disease. Prog Neuropsychopharmacol 33: 308-311.

Murakami Y, Zhao Q, Harada K, Tohda M, Watanabe H, Matsumoto K. 2005. Chotosan, a Kampo formula, improves chronic cerebral hypoperfusion-induced spatial learning deficit via stimulation of muscarinic M1 receptor. Pharmacol Biochem Behav 81: $616-625$.

Nishino S, Mignot E, Dement WC. 1995. Sedative hypnotics. In: Schatzberg AF, Nemeroff CB (eds). The American Psychiatric Press Textbook of Psychopharmacology. American Psychiatric Press: Washington, DC; pp 405-416.

Nukaya H, Yamashiro H, Fukazawa H, Ishida H, Tsuji K. 1996. Isolation of inhibitors of TPA-induced mouse ear edema from Hoelen, Poria cocos. Chem Pharm Bull 44: 847-849.

Obrenovitch TP, Urenjak J. 1997. Altered glutamatergic transmission in neurological disorders: from high extracellular glutamate to excessive synaptic efficacy. Prog Neurobiol 51: 39-87. 
Oh MH, Houghton PJ, Whang WK, Cho JH. 2004. Screening of Korean herbal medicines used to improve cognitive function for anti-cholinesterase activity. Phytomedicine 11: 544-548.

Okamoto H, Okami T, Ikeda M, Takeuchi T. 2004. Effects of Yoku-kan-san on undifferentiated somatoform disorder with tinnitus. Eur Psychiatry 20: 74-75.

Prinz PN, Peskind ER, Vitaliano PP, Raskind MA, Eisdorfer C, Zemcuznikov N, Gerber CJ. 1982. Changes in the sleep and waking EEGs of nondemented and demented elderly subjects. J Am Geriatr Soc 30: 86-93.

Satlin A, Teicher MH, Lieberman HR, Baldessarini RJ, Volicer L, Rheaume Y. 1991. Circadian locomotor activity rhythms in Alzheimer's disease. Neuropsychopharmacol 5: 115-126.

Schapera CH. 2003. Potential causes of secondary hypertension. Am Fam Physician 68: 42.

Schneider LS, Dagerman K, Insel PS. 2006. Efficacy and adverse effects of atypical antipsychotics for dementia: meta analysis of randomised, placebo-controlled trials. Am J Geriat Psychiat 14: 191-210. 
Seibyl JP, Glazer WM, Innis PB. 1989. Serotonin function in tardive dyskinesia, Psychiatr Ann 19: 310-314.

Shimada Y, Goto H, Itoh T, Sakakibara I, Kubo M, Sasaki H, Terasawa K. 1999. Evaluation of the protective effects of alkaloids from the hooks and stems of Uncaria sinensis on glutamate-induced neuronal death in cultured cerebellar granule cells from rats. J Pharm Pharmacol 51: 715-722.

Shinno H, Inami Y, Inagaki T, Nakamura Y, Horiguchi J. 2008. Effects of Yi-Gan-San on psychiatric symptoms and sleep structure at patients with behavioural and psychological symptoms of dementia. Prog Neuropsychopharmacol 32: 881-885.

Sigurjonsdottir HA, Ragnarsson J, Franzson L, Sigurdsson G. 1995. Is blood pressure commonly raised by moderate consumption of licorice? $J$ Human Hyperten 9: 345-348.

Smriga M, Saito H, Nishiyama N. 1995. Hoelen (Poria cocos Wolf.) and ginseng (Panax ginseng C.A. Meyer), the ingredients promote hippocampal long-term potentiation in vivo. Biol Pharm Bull 18: 518-522.

Steele C, Rovner B, Chase GA, Folstein M. 1990. Psychiatric symptoms and nursing home placement of patients with Alzheimer's disease. Am J Psychiatry 147: 10491051. 
Sun X, Chan LN, Gong X, Sucher NJ. 2003. N-methyl-D-aspartate receptor antagonist activity in traditional Chinese stroke medicines. Neurosignals 12: 31-38.

Tabuchi M, Yamaguchi T, lizuka S, Imamura S. 2009. Ameliorative effects of yokukansan, a traditional Japanese medicine, on learning and non-cognitive disturbances in the Tg2576 mouse model of Alzheimer's disease. J Ethnopharmacol 122: $157-162$.

Takeda A, Itoh H, Tamano H, Yuzurihara M and Oku N. 2008. Suppressive effect of Yokukansan on excessive release of glutamate and aspartate in the hippocampus of zinc-deficient rats. Nutr Neurosci 11(1): 41-46.

Tateno M, Ukai W, Ono T, Saito S, Hashimoto E, Saito T. 2008. Neuroprotective effects of Yi-Gan San against beta amyloid-induced cytotoxicity on rat cortical neurons. Prog Neuropsychopharmacol 32: 1704-1707.

Terasawa K. 2004. Evidence-based Reconstruction of Kampo Medicine: Part II—The Concept of Sho. eCAM 1(2): 119-123.

Tohda C, Tamura T, Komatsu K. 2003. Repair of amyloid $\beta(25-35)$-induced memory impairment and synaptic loss by a Kampo formula, Zokumei-to. Brain Res 990: 141147. 
Wainwright J, Schonland M, Candy H. 1977. Toxicity of Callilepis laureola. S Afr Med J 52: 313-315.

Weikert S, Freyer D, Weh M, Lsaev N, Busch C, Schultze J, Megow D. 1997. Rapid Ca2+-dependent NO-production from central nervous system in culture measured by NO-nitric/ozone chemoluminescence. Brain Res 748: 1-11.

Yabe T, Torizuka K, Yamada H. 1995. Effects of kampo medicines on choline acetyltransferase activity in rat embryo septal cultures. J Trad Med 12: 54-60.

Yahara S, Higashi T, Iwaki K, Nohara T, Marubayashi N, Ueda I, Kohoda H, Goto K, Izumi H, Nuno M, Katsuki S, Isoda S, Satake M. 1989. Studies on the constituents of Atractylodes lanea. Chem Pharm Bull 37: 2995-3000.

Zhao Q, Murakami Y, Tohda M, Watanabe H, Matsumoto K. 2005. Preventive effect of Chotosan, a Kampo medicine, on transient ischemia-induced learning deficit is mediated by stimulation of muscarinic M1 but not nicotinic receptor. Biol Pharm Bull 28: $1873-1878$.

Zhao Z, Wang W, Guo H, Zhou D. 2008. Antidepressant-like effect of liquiritin from Glycyrrhiza uralensis in chronic variable stress induced depression model rats. Behav Brain Res 194: 108-113. 